\title{
BURNOUT OF SOCIAL WORKERS AT Dr. HASAN SADIKIN BANDUNG CENTRAL HOSPITAL
}

\author{
Radityo Bimo Kartiko Aji \\ Bandung Polytechnic of Social Welfare (Poltekesos), Ir. H. Juanda Street (Dago), No. 367, \\ Bandung, radityobka@gmail.com \\ Meiti Subardhini \\ Bandung Polytechnic of Social Welfare (Poltekesos), Ir. H. Juanda Street (Dago), No. 367 \\ Bandung, meiti.subardhini@gmail.com \\ Yana Sundayani \\ Bandung Polytechnic of Social Welfare (Poltekesos), Ir. H. Juanda Street (Dago), No. 367 \\ Bandung, yanasundayani@yahoo.com
}

\begin{abstract}
The high workload can cause burnout. Burnout makes the worker not pay attention to the person he helped, thus reducing the quality of service. The research method used is descriptive research method with qualitative approach. The informant consisted of 11 people, two medical social workers, three medical social worker partners, and six medical social worker patients. The result of the research showed that: a) medical social workers experiencing burnout with the most emerging aspect of emotional exhaustion, b) depersonalization aspects, medical social workers showed apathetically and acting callous at work, c) medical social worker feel they can't work optimally but in the reality, they have good performance based on Indeks Kinerja Individu (IKI), d) Medical social worker can keep working with good performance because of their love to the profession, e) The burnout shown by medical social workers has no effect to the helping process to the patient in Dr. Hasan Sadikin General Hospital. The main factors of burnout of medical social workers is a barrier in their career, which leads the medical social worker can't get their rights based on their performance and education.
\end{abstract}

Keywords:

Burnout, Medical Social Worker, Hospital. 


\section{INTRODUCTION}

Burnout is a condition where a person cannot carry out his activities to the maximum. "Burnout is a state of mind accompanied by various symptoms such as emotional, physical and psychological fatigue; feelings of hopelessness and loss of enthusiasm for work and even for the spirit of life "(Pines and Aronson in Edi Suharto, 2009 , p. 53). Burnout is in fact not easy to see. Someone who experiences burnout from the outside can look mediocre, but from the inside, there are many problems that affect it. Burnout can also attack anyone regardless of age and occupation.

Burnout can cause workers or employees to not pay attention to the people they help. Physical fatigue and emotional exhaustion are signs of burnout. This emotional fatigue is characterized by no longer having positive feelings, sympathy or respect for the client he helped (Maslach and Pines in Edi Suharto, 2009).

Bakker and Costa stated that "employees who are at risk at burnout show impaired job performance and may face serious health problems over the course of time" (Bakker and Costa, 2014, p. 112). Workers who experience burnout will show decreased work performance and can face serious health problems over time.

Social workers are professions that are recorded as being prone to burnout (Gillespie, 1987). Prone because social workers are professions that deal directly with humans as clients. Clients who have their own uniqueness and cannot be compared to one another become a challenge. Social workers are defined as methods to restore and improve a person's social functioning (Siporin in Fahrudin, 2012). Burnout experienced by social workers can affect the services provided to clients. This certainly becomes contrary to the Social Workers Code of Ethics Article 4 Letter $\mathrm{b}$ states that social workers "provide the best possible service in accordance with their professional abilities". Social workers cannot provide services according to standards when experiencing burnout.

Yusuf in his 2011 research said that workload has an influence on work saturation. This is because social workers feel the level of difficulty in dealing with clients with disabilities is higher and varied when compared to social work practices in other settings. The number of clients of social workers also has an influence on the burden they feel (Yusuf, 2011). Joseph's research illustrates that social workers sometimes have high workloads. The high workload can be one of the causes of burnout. The setting of social worker services can also be a factor influencing the burnout of social workers, as for medical social workers at RSUP Dr. Hasan Sadikin also handles disability patients. Including physical, mental, hearing and / or speech disabilities, as well as intellectual disabilities.

Medical social workers in Indonesia have actually been realized and implemented in several hospitals. Law of the Republic of Indonesia number 36 of 2009 concerning Health, Chapter 1 Article 1 Paragraph 1 states that "health is a healthy state, both physically, mentally, spiritually and socially that enables everyone to live productively socially and economically." This paragraph emphasizing that one's health is seen as a 
whole, not only physical health but also mentally, spiritually and socially. The social side that needs attention is in accordance with the understanding of medical social workers by Barker, namely "the social work practice that occurs in hospitals and others health care settings to facilitate good health, prevent illness, and help physically patients and their families to resolve the social and psychological problems related to illness "(Barker in Fahrudin, 2009, p. 3).

The symptoms of burnout itself include cynicism, negativity, and rigidity in thinking (Freudenberger in Suharto, 2009). The decline in service quality is one of the many consequences caused by burnout. The decline in service quality will have a negative impact on workers and workplaces. Based on the results of interview researchers at the Central General Hospital (RSUP) Dr. Hasan Sadikin told social workers that the average number of social workers in hospitals in Indonesia ranges from one to three people per hospital. RSUP Dr. Hasan Sadikin has two social workers working under the Medical Rehabilitation Installation (IRM). This medical social worker at IRM is in accordance with Minister of Social Decree number 378 / Menkes / SK / 2008 concerning Guidelines for Medical Rehabilitation Services in Class A, B, C and D. Hospitals Dr. Hasan Sadikin as a national level referral hospital can serve patients in and outside West Java Province. Based on the interview results it is known that the Medical Rehabilitation Installation receives referrals from all sections in Dr. Hasan Sadikin, the number of outpatients can reach an average of above 1000 people each day. These patients are spread over several services. one of them in the Medical Rehabilitation Installation.

IRM in accordance with the plant head's policy makes all new patients must be referred to medical social workers in order to know the social conditions of patients to be handled by the IRM team.

RSUP Dr. Hasan Sadikin has a status as a teaching hospital. This status makes many educational institutions that collaborate with Dr. RSUP Hasan Sadikin for practical and learning activities. This makes every year there is a change of resident doctors, namely prospective specialist doctors. This routine doctor turnover makes social workers need to reexplain the duties and functions of the social work profession in accordance with Operational Standards and Procedures (SPO). This is a challenge because of the large number of resident doctors present and spread across a variety of services at RSUP Dr. Hasan Sadikin so that the socialization of the profession and the task of medical social workers have not been maximized. The medical social worker at RSUP Dr. Hasan Sadikin has several tasks that must be performed, including social assessment, social consultation, social guidance, outreach or home visit, coordination with professions and other parts within the Dr. RSUP. Hasan Sadikin and also coordinated with other institutions outside the hospital for the needs of patients, such as charities and the Social Service. These tasks are all carried out by two medical social workers at Dr. Hasan Sadikin Central Hospital.

Based on the results of interviews, social workers find it difficult to be able to divide their time between conducting patient 
services in the hospital and making visits or home visits outside the hospital. Both tasks must be carried out during working hours.

Medical social workers have also made a home visit to the border of West Java Province. Medical social workers in providing services to patients in the hospital can spend hours. This is due to the need for an in-depth assessment of the patient and family to help solve the patient's problem. The medical social worker at RSUP Dr. Hasan Sadikin also carried out structural tasks such as the person in charge of counseling and treasurer IRM.

The duties and functions of the social worker make the possibility of social workers in RSUP Dr. Hasan Sadikin experienced high burnout. Social workers are limited by the number and workload that is quite a lot to make the services provided can not be maximized. Social workers who are under the auspices of the two ministries, namely the Ministry of Social Affairs and the Ministry of Health also make the promotion of the group experience obstacles so that it can reduce the morale of medical social workers. Calculation of the occurrence of burnout can not only be seen from the number of clients handled because the ability of each person is different. Researchers found a study conducted by Unison and Community Care in the UK that caseload can be a contributing factor to burnout. Caseloads or caseloads that are high enough can cause burnout to medical social workers. In 2009 the Laming Review issued a recommendation that workers working in child settings do not have caseloads or cases over 13 cases. Medical social workers, although not in the setting of children, but deal with children and also adult patients. The high caseload is only carried out by two medical social workers.

\section{METHOD}

The design of this research is qualitative with the aim of gaining depth and understanding of the burnout of medical social workers. The formulation of the problem used in this research is descriptive. The strategy used by the researchers was a case study of two medical social workers in the Medical Rehabilitation Installation (IRM) of RSUP Dr. Hasan Sadikin. There were 11 informants who provided information in this study, with two medical social workers, three working partners, and six patients. Data analysis techniques using data reduction, data presentation, drawing conclusions and verification.

\section{RESULT AND DISCUSSION}

The results showed that the burnout of medical social workers was shown in aspects of emotional exhaustion, depersonalization, and low achievement of individual social workers. The causes of social worker burnout vary. Mainly caused by obstacles in career.

\section{Emotional Fatigue}

Emotional fatigue is an aspect of burnout. When conducting research on emotional aspects, researchers get various answers from medical social workers and other informants. Emotional fatigue is an endless source of emotional resources within the individual which is characterized by feelings of frustration, despair, sadness, feeling saturated, irritable, easily feeling tired and feeling 
difficult at work (Maslach and Leiter, 2016). Other experts consider that failure is the essence of the burnout process (Caputo, 1991).

Emotional fatigue experienced by social workers is shown by feelings of frustration, despair, sadness, saturation, irritability, feeling trapped in work, and easily tired. These feelings and behaviors are observed by the researcher and expressed directly by the informant to the researcher. Emotional fatigue experienced by medical social workers the biggest cause is the incompatibility between the sacrifices that have been given with the goals achieved. This is consistent with the opinion of experts who say that dedication and idealism are too high to make someone try too hard and cause fatigue and cynicism when their goals cannot be achieved (Maslach, Schaufeli, and Leiter, 2001). Other causes are stunted careers, medical social workers sheltered by two ministries, no professional legislation, and a lot of work done.

\section{Frustration}

Frustration is caused by inappropriate expectations and the reality obtained. The frustration experienced by medical social workers can be broken down into two parts, namely frustration due to obstruction of the career of medical social workers and patients not being a cause of frustration for medical social workers.

The frustration felt by medical social workers was caused by several things such as changes in rank regulations, mutual appointments between ministries, no laws, and lack of support from professional associations. Obstacles to careers make medical social workers where their rights to income and rank in accordance with their obligations are not obtained. Medical social workers have also taken various ways so that their careers can improve again.

Changes in rank regulations are also one of the causes of frustration. The results of the study show that since the change in rank and rank rules with credit scores, the career of one of the social workers is hampered to 17 years. The frustration felt related to rank is also because medical social workers see work partners who work no longer than medical social workers but can be higher in rank than medical social workers.

Inter-ministry referrals are shown by the lack of a clear credit rating system from medical social workers because medical social workers are given a decree by the Ministry of Health but social workers are a profession that is under the Ministry of Social Affairs in this case the Functional Position Development Center (Pusbinjabfung) so that the assessment process often experiences confusion. The absence of a social worker law also prevents medical social workers from having a Registration Certificate (STR) issued by the Indonesian Board of Health Workers (MTKI). STR is useful so that the services performed by health workers become legal and have legal protection.

Medical social workers feel that support from professional associations is still not felt. Medical social workers also feel that they still have not enough effort in coordinating with professional 
associations because they have to deal with patients in the hospital. Hampering the career of medical social workers does not only occur in Dr. Hasan Sadikin Central Hospital, but it also happens in all hospitals where there are social workers. These career obstacles can be one of the causes of frustration experienced by medical social workers who can affect the services provided at the Medical Rehabilitation Installation (IRM).

Patients are not the cause of frustration because there is good teamwork at the Medical Rehabilitation Installation (IRM) and realistic expectations of social workers for the goals of patient care. Patients in the Medical Rehabilitation Installation also receive services from other work teams, namely Psychologists and therapists according to the references given by the Doctor in Charge of Services (DPJP), so that the services provided can be complete for patient health. Teamwork also allows medical social workers to be able to discuss the obstacles experienced by patients to get joint solutions from the Medical Rehabilitation Installation team.

Medical social workers in providing services to patients always try to the maximum. When the services that have been given cannot reach the stated goals, the medical social worker is not too concerned. Experience teaches many medical social workers in dealing with patients in the Medical Rehabilitation Installation.

\section{Despair}

Despair is a feeling of hopelessness or loss of hope from someone. Desperate workers can certainly affect the service because they no longer have the motivation or hope for the work done. Desperate description of the results of the study, namely medical social workers are not desperate in providing services to patients and despair could exist because of the obstruction of the career of medical social workers.

Patients served by medical social workers have their own uniqueness. The uniqueness here in providing services makes medical social workers unable to equate services between one patient and another patient. Medical social workers also feel that they never give up on serving patients. Reasons that make social workers not give up in serving patients one of them is a discussion with other professions and superiors at the hospital.

In contrast, medical social workers have felt hopeless about obstacles in their careers. The despair felt by medical social workers was motivated because they had not gone up in rank for a long time. AN for 17 years has not moved from III-D and FT who have master's degrees but their class is still II-C.

\section{Sadness}

Medical social workers at work also experience sadness. This feeling of sadness supports the reality that the medical social worker profession does not appreciate. Feelings of displeasure that cause sadness arise because of a hampered career, medical social workers who are not known in the workplace themselves and also who are not appropriate. Medical social workers are sad because their rank is hampered even 
though they have worked hard for the hospital. The FT informant himself decides on the rank problem to get fast, he can get class III-C or III-D and AN can be group IV after his agreement has been carried out. This prevents medical social workers from having the right to speak.

Medical social workers feel that their role and performance can already be felt by the hospital. Patients who need financial assistance and assistive devices when the hospital cannot provide assistance by medical social workers, patients who cannot be discharged due to neglect or families who do not pick up are also employed by medical social workers, confused parents deal with children who are special needs are also assisted by medical social workers. Participation in advancing the profession and hospital has been carried out by medical social workers but unfortunately, until now medical social workers are still rarely known by other professions in their own workplaces.

However, even though medical social workers experience sadness at work, medical social workers still provide maximum service to their patients. This makes it comfortable for patients to come to medical social workers.

\section{Saturation}

Medical social workers experience saturation while working is caused due to obstacles in their career and medical services condition. Saturated by career barriers themselves felt by medical social workers because medical social workers feel they do not have the power of the rank system and expectations that are not in accordance with reality. Medical social workers feel that they are entitled to get more than what they have now based on the length of their service and also levels. education that they take in order to maximize services at the Dr. Hasan Sadikin. The expectation that medical social workers have is certainly not wrong, but this hope cannot be fulfilled by hospitals because of the limitations of the existing system.

Medical social worker service conditions also cause workers to feel bored. Working indoors continues to be one of the causes. Medical social worker services for pediatric patients are dominated by outpatients. This makes pediatric medical social workers spend more time indoors, thus making saturated. Medical social workers' child services in a day can provide services to 1-3 patients. Each service itself takes 1-2 hours.

On the contrary, adult social service medical workers experience burnout due to frequent visits outside for the treatment of patients. Outward visits meant are visits to other institutions such as the Social Service, shelter, Tresna Werdha Social Protection Center (BPSTW) and other institutions. This work is done alone because medical social workers with each other have their respective responsibilities.

\section{Angry tendencies}

Workers who have a tendency to get angry easily become a "bomb" time on the services they provide. The tendency to anger medical social workers emerge because of obstacles in his career. The 
results of the study showed one social medical worker has a tendency to get angry because social workers feel they have the right to increase prices self and his own well-being, but that is not valued and has not been fulfilled by the hospital, which causes him to get angry easily.

The tendency to be angry easily medical social workers themselves do not affect service to patients. This is caused by the self-awareness of medical social workers. Medical social workers realize that good communication is one way to help patients.

Medical social workers can restrain themselves and respect the patient's presence so that the tendency to get angry easily because work is not overflowed with patients. Social workers also realize that patients are people who need help, and being easily angry with patients will not help much in the process of help.

\section{Feel trapped in a job}

The results showed that medical social workers felt trapped in service. Social workers who feel trapped make social workers become depressed about the tasks that must be done. Expectations from various sides also make medical social workers feel trapped in their work.

The number of medical social worker patients that is not balanced with the number of medical social workers is one reason medical social workers feel trapped. This is due to the policy of the Medical Rehabilitation Installation that new patients will be referred to as medical social workers. This makes medical social worker patients available almost every day, not to mention if it is added to inpatients. Medical social workers in Dr. Hasan Sadikin have each target if the target FT informant is 24 outpatients and four inpatients are different from AN informants who have a target of four outpatients and 23 inpatients. Patients served by medical social workers also have different problems and require different problem-solving.

Pressure from other professions is also felt by medical social workers and makes workers feel trapped in their work. The pressure felt primary comes from doctors, especially residents and also the part of financial administration. Medical social workers feel that the pressure from the main resident doctor in the psychiatric room makes him feel depressed and feel trapped in work. This is because resident doctors have a certain time limit to provide service as much as possible and make the patient can return to the most optimal condition. Pressure from the administration usually arises when there are patients who are not picked up because of financial problems then the assigned social medical worker. The medical social worker is also a liaison with the Social Service to take care of the cost of exemption patient costs cannot be afforded, so medical social workers often make outside visits to take care of this.

\section{Easily fatigued}

Medical social workers often feel easily fatigued due to burnout. Easily tired due to busyness inside and outside the hospital is also due to working conditions. One informant revealed that he sometimes 
had difficulty dividing his time between work inside and outside the hospital which cannot be left behind.

Easily tired of medical social workers are also caused by the number of patients and also the separation of social work service rooms. The number of patients handled by medical social workers varies per day, but on average ranges from one to three patients. The fatigue experienced is not only physical fatigue but also mental fatigue because many patients who must be treated have their own uniqueness. This makes the medical social worker quite drained his mind.

The separation of the service room also makes medical social workers feel more easily tired. Since a few years ago the service room of child and adult medical social workers was separated. This made it difficult for medical social workers to divide tasks due to having the responsibility of each patient.

According to researchers, the main cause of emotional fatigue experienced by medical social workers is an obstacle in his career. This obstacle in his career makes medical social workers experience frustration until they get tired easily. this and maybe even in the future. The main cause of emotional fatigue is social workers who work in the secondary service setting, which is the hospital. Medical social workers in the hospital are certainly not given much attention compared to social workers in the primary setting. Medical social workers only assist in service, and not be the main actor in service that aims to cure patients so that sometimes the award received is not in accordance with the expectations of medical social workers. This is also supported by the expert opinion which says that burnout is more due to working conditions rather than factors personal person (Gilespie, 1987). Supporting factors that make emotional fatigue not too developed based on the results of the research are good working conditions and partners working together. This is also in accordance with the opinion of experts who say that a good social support system can be used as a deterrent to burnout (Maslach in Suharto, 2006 ). Social support systems such as those owned by medical social workers with their partners can be a means of sharing experiences, socializing and being a source of security and help.

\section{Depersonalization}

Depersonalization is the tendency of individuals to stay away from their social environment, to be cynical, apathetic and unfeeling (Maslach and Leiter, 2016). Medical social workers who move away from their environment will find it difficult to provide maximum service to their patients. This is consistent with the expert opinion which states that social workers who are cynical, apathetic and unfeeling can also make the conditions of the work environment not conducive (Maslach, Schaufeli, and Leiter, 2001). Depersonalization is one aspect of the burnout of medical social workers. research shows that medical social workers do not move away from their environment, are not cynical, but are apathetic and have acted heartless in working for their superiors. 


\section{Not away from the environment}

The opinion of the expert states that social and physical isolation in the world of work is one of the other variables identified by burnout (Larson, Gilbertson, and Powell in Gilespie, 1987). Workers who move away from their environment are one of the sub-aspects of personalization. Workers who move away from their environment can make the work he does not be optimal. Workers who move away from his environment can also make working conditions not conducive. Based on the results of medical social medical research workers do not move away from their environment. This can be realized by the way medical social workers always introspect themselves, tell stories with people they trust and pray.

A medical social worker by introspecting himself makes every problem he experiences can be resolved as quickly as possible and does not interfere with his work at RSUP Dr. HasanSadikin. Selfintrospection carried out by medical social workers also help medical social workers not move away from their environment. Another thing that causes social workers not to stay away from their environment when burnout is the habit of telling stories with people they trust. Social medical workers reveal that when there are problems at work or outside their work will be told to the person he trusts. This helps social workers not moving away from their environment. Even though they do not always get solutions but by conveying problems experienced by workers makes social workers in carrying out their work calmer. The habits of medical social workers tell each other to help medical social workers alleviate their problems. The two medical social workers who have known each other for a long time and also become partners also make them understand each other.

Based on the statement of the research informant as a whole, it revealed that medical social workers did not move away from the environment when working at RSUP Dr. Hasan Sadikin. Self-awareness of the social worker makes him aware that if he moves away from his environment, then it can lead to working conditions that are not conducive and does not support the service process provided to patients. This is certainly a good condition, even though medical social workers are experiencing emotional exhaustion. Medical social workers do not move away from their environment so that the service process can be run.

\section{Not being cynical}

Cynicism is an attitude of looking down on someone else. Workers who have a tendency to be cynical can not only disrupt a conducive work atmosphere, can also make patients feel unappreciated. The social medical worker herself works in Dr. Hasan Sadikin does not have a tendency to be cynical.

Cynicism is not shown by social workers primarily because of the professionalism held by medical social workers. The professionalism of medical social workers makes medical social workers not cynical despite experiencing a turnout. When working at Dr. Hasan 
Sadikin despite experiencing emotional exhaustion. Medical social workers are not cynical because they are aware that medical social workers must maintain a conducive working atmosphere in supporting maximum service. Medical social workers also understand that patients are people who need to be given help and look down on patients, certainly cannot help solving problems.

\section{The apathetic attitude of medical social workers.}

Apathy makes workers insensitive and unable to see their environmental conditions. Medical social workers in the results of this study show apathy. Apathy is shown to the hospital management due to obstacles in his career. from medical social workers at RSUP Dr. Hasan Sadikin to the Regional Government (PEMDA).

The desire to strike had been influenced by medical social workers. This desire arises because of obstacles in his career and also the lack of encouragement from the human resources of the hospital, which could not do much due to regulatory factors that do not support. Work strike is considered to be a solution so that the rights of social workers medical can be fulfilled. In fact, it is only limited to the desire and action has never been done. Medical social workers still want to show the best performance so that this profession becomes more advanced in the hospital with all the obstacles.

The desire of medical social workers to move to work shows that medical social workers do not care about their work in hospitals. Medical social workers assume that the hospital does not care for them. Social work partners say that the apathy shown is only a momentary emotion due to feelings of anger and disappointment about his departure.

Based on the research results it is also known Based on the research results it is also known that medical social workers do not show a tendency to be apathetic towards patients. Medical social workers understand that being apathetic towards patients will only harm the medical social worker himself because he can get a reprimand from the patient or from the installation.

\section{The tendency to act unfeeling}

The tendency to act callously from medical social workers can make working conditions unfavorable. Medical social workers when acting unfeeling to patients can also make services become bad grades in the eyes of patients. One social worker once acted unfeelingly to his superiors at RSUP Dr. Hasan Sadikin because he was upset with his appointment, but this did not last. The results of the study revealed that social workers did not show a tendency to act unfeeling to their patients. Patients from medical social workers also confirmed this.

\section{The Achievement of Individual Medical Social Workers}

The low personal achievement is described as reduced productivity, feeling not optimal and the inability to deal with problems (Maslach and Leiter, 2016). Low individual achievement is one aspect of burnout that will be examined by medical social workers. Medical social 
workers who experience a turnout can result in their achievment in working is low and not in accordance with existing standards.

\section{Feeling not optimal in providing services}

Medical social workers in providing services to patients in Dr. Hasan Sadikin felt that it was not optimal. The cause of the lack of medical social workers in providing services was due to the lack of medical social workers and the separation of medical social worker rooms.

Medical social workers in providing services in the Medical Rehabilitation Installation feel not optimal due to a lack of human resources medical social workers. Lack of Human Resources (HR) causes the services provided to be incomplete. cannot be done completely. The monitoring and evaluation phase of patients with home visits is not carried out because they are supposed to serve outpatients almost every day at the Medical Rehabilitation Installation.

The results showed that at the time of medical social workers numbered four people a few years ago, medical social workers can divide their work so that home visiting services to patients can be done without leaving the responsibility of serving outpatients. Now medical social workers cannot carry out home visiting services to patients because if it is done outpatients that exist every day can not be handled. Medical social workers also emphasize that home visits are services that make assistance to patients become plenary. Home visits make medical social workers can monitor the implementation of programs that have been given at the Medical Rehabilitation Installation and also get information that might not be obtained during service at the hospital. Currently, medical social workers for home visits sometimes ask for help from the District Social Welfare Workers (TKSK), sometimes the results obtained are not appropriate.

Medical social workers also feel the lack of human resources makes the service not optimal when medical social workers become unable to focus because many patients also have to think about it. When medical social workers do an out visit sometimes there are patients who come and must be rescheduled on other days. making services not optimal because social workers can not be in two places at the same time to perform services outside the hospital and inside the hospital.

Medical social workers also feel that when a service room is combined, services become more maximal. Medical social workers can help each other and collaborate with each other and divide tasks according to their needs. dividing tasks among medical social workers themselves.

\section{No decline in the productivity of} medical social workers

The decline in worker productivity is certainly not expected by the institutions that employ workers. The results of the study showed that the productivity of medical social workers did not decrease.

In the medical social worker service schedule sometimes there are a few days that are emptied of patients. Emptying the 
day on the patient's schedule is not done for not working or reducing the productivity of medical social workers. An empty day is sometimes used to visit the referred inpatients to medical social workers, but this is also flexible with the presence or absence of outpatients who must be served on that day. Based on the observation of researchers if there are no inpatient referrals, medical social workers will still be in his room.

No decline in medical social worker IKIs is one form of non-decline in the productivity of medical social workers. The productivity of medical social workers can be seen from the service targets achieved within one month and can be observed through the Individual Cumulative Index (IKI). The decline occurred in June 2018, but it was due to a holiday break of about 1 week more so that the target patients treated were not achieved. It can be illustrated that the productivity of medical social workers when viewed from IKI is good, tends to be stable and does not decrease. Targets that have been written by medical social workers based on their job description can also be achieved. This illustrates that burnout that occurs in medical social workers does not affect medical social worker services for patients.

\section{No difficulty in overcoming the problem}

Workers who have difficulty dealing with problems certainly can also find it difficult to deal with problems from others. Medical social workers working at Dr. Hasan Sadikin are faced every day with various problems experienced by his patients and medical social workers are expected to be able to help these patients deal with their problems.

Learning new theories and techniques is one way for medical social workers to overcome their problems. Medical social workers feel that by re-learning there are problems that can be solved. Medical social workers feel that partners are one of the reasons medical social workers can face problems at work. Conditions of a conducive work environment make medical social workers can discuss with partners work partners. This is in accordance with the opinion of experts who say that good social support helps a person prevent burnout (Maslach in Suharto, 2006). This makes the problem experienced by medical social workers in working in RSUP Dr. Hasan Sadikin can be overcome so that it does not reduce the quality of service.

The tendency of burnout medical social workers is shown from the sub-aspects that feel not optimal at work. This feeling arises for two reasons. First, medical social workers feel that the lack of human resources for medical social workers causes services that cannot be wholly and sometimes patients become late to be treated. Medical social workers who only have 2 for RSUP Dr. Hasan Sadikin limited medical social workers when providing services. When medical social workers went out for a visit, the outpatient service room was empty without anyone. This sometimes made patients who came have to wait or even reschedule their meetings with medical 
social workers again. This was not felt when there were still 4 medical social workers in RSUP Dr. Hasan Sadikin. Medical social workers can divide tasks and work together in caring for their patients. The separation of medical social worker service rooms is the reason the services provided are less than optimal. cooperate and divide their duties.

\section{Medical Social Workers in Overcoming Burnout}

The medical social worker at RSUP Dr. Hasan Sadikin felt that he experienced burnout, especially from the aspect of emotional exhaustion. Despite experiencing burnout services from medical social workers did not experience a decline. This is because medical social workers have their respective ways of handling the impact of burnout that he felt. The professionalism of social workers is expressed in the results of research in various forms. Professionalism is one of the social workers to overcome burnout. The first way medical social workers in handling burnout they feel are to stick to the professionalism of their profession in various obstacles.

Medical social workers despite career obstacles continue to do their jobs so that the medical social worker profession is still seen as a professional profession. Medical social workers despite experiencing burnout, medical social workers continue to uphold their professionalism. This is what helps medical social workers do not degrade the quality of their services. Social workers the medical cannot do much because of career obstacles that cause burnout of medical social workers, so he does not want his profession to be dimmed due to his poor performance because he is not professional.

Based on the results of the study note that the main reason for medical social workers to maintain professionalism in work is a love of the profession and want to increase the degree of the profession of social workers, especially in the medical setting. Medical social workers show that he is not looking for anything in working at RSUP Dr. Hasan Sadikin because of his senior age and also he was always grateful to be able to work in a profession that he loved for more than 29 years. The love of the profession became a reinforcer from within the social worker so that he could maintain the quality of his services despite experiencing burnout. Based on the results of research social workers are less appreciated in the medical setting in hospitals, other than because there is no strong legal umbrella for medical social workers; also because there are still professions in the RSUP Dr. Hasan Sadikin who actually did not understand the main tasks and functions of medical social workers. This makes medical social workers feel less appreciated because of the existence of Operational Procedural Standards (SPO). A good work climate helps medical social workers face burnout. A good work climate allows medical social workers to be able to discuss and also tell stories when medical social workers experience obstacles in their work. 


\section{Medical Social Worker Expectations}

The various work demands with limited time and human resources make medical social workers in Dr. Hasan Sadikin is prone to burnout. This should be a concern of institutions where social workers work to prepare precautions so that social workers do not experience burnout.

The expectation of the first medical social worker is that his assignment can be completed and the medical social worker can get his rights in accordance with the obligations undertaken. It is known that the main expectation of medical social workers in working in Dr. Hasan Sadikin is the resolution of the rank problem in accordance with the obligations that have been carried out by medical social workers. Medical social workers who do not get the right to the appropriate rank can cause burnout which will later have a long impact and will affect the services provided to patients.

Medical social workers have also been grateful that the profession of medical social workers can gradually be recognized in Dr. Hasan Sadikin. Patients who pay to consult medical social workers have been perceived as being rewarded for their profession. Medical social worker services that are also listed on the BPJS claim sheet that read ICD 93.89 have become a recognition from the government of the social worker's profession, unfortunately, the rank of medical social workers who still have no clear resolution becomes an obstacle for medical social workers to exist in the hospital.
Based on the results of the study no doubt the addition of social workers can help medical social workers face burnout they experienced. Medical social workers want new medical social workers to share tasks, especially external tasks. Opening new social medical workers can also help social workers' medical division of their duties so that a complete service is achieved.

\section{The Analysis of Medical Social Worker} Burnout Problems

Burnout experienced by medical social workers at RSUP Dr. Hasan Sadikin is a condition that occurs due to various factors that accumulate during medical social work. There are also conditions that are not supportive of social workers to carry out their work. This problem presents other problems for medical social workers. As for the problems that need solving as soon as possible as follows.

The results of research on emotional fatigue experienced by medical social workers at RSUP Dr. Hasan Sadikin consists of several conditions. The conditions experienced by social workers include feeling frustrated, sad, bored, easily irritated, feeling trapped in work and easily tired is a feeling of emotional fatigue that arises in medical social workers. and appreciation for the profession sometimes makes this feeling even bigger and can affect the service of medical social workers. The profession of medical social workers who, although they have long been in the RSUP Dr. Hasan Sadikin but still unknown to his own workers is also one of the causes of emotional fatigue for medical social 
workers. Social workers who experience emotional fatigue are good institutions where medical social workers work together with medical social workersand professional associations looking for a way out of the problem problem mainly from the rank and appreciation of the profession so that this does not become protracted emotional fatigue that can affect the service of patients.

The results of research on depersonalization experienced by social workers in Dr. Hasan Sadikin only happened to one informant only. The impact of depersonalization although it has not been felt until now, if allowed to drag on without handling it can disrupt a conducive work atmosphere in order to provide services to patients. Medical social workers who experience depersonalization can stay away from their environment, be cynical, apathetic and even act heartless. This can cause problems in the service process, even though depersonalization is only experienced by one informant.

The results of research on the low personal achievement of medical social workers show that medical social workers experience this. The two main informants revealed that the services provided to patients have not been maximized due to lack of human resources so that services to patients cannot be carried out in a complete manner according to the stage of social worker assistance. The separation of medical social worker service rooms also makes it difficult for medical social workers to cooperate in carrying out services to patients.

\section{Medical Social Worker Needs to Overcome Burnout}

Burnout conditions experienced by medical social workers are the accumulation of various needs that have notbeen made to resolve the factors that can prevent burnout from medical social workers, so based on the results of research and problem analysis, researchers see that there are several needs that can help in alleviating burnout experienced by medical social workers, as for the needs that needed in the prevention of burnout problems, medical social workers are as follows.

The need to overcome the emotional fatigue of medical social workers according to researchers is the activities carried out outside the hospital to refresh the body and soul of medical social workers to get a new atmosphere. Activities undertaken are also expected to provide benefits for scientific development and knowledge for workers social medical in dealing with the obstacles that cause burnout. Long-term things that must be done by related institutions are handling the problem of career obstruction of medical social workers. According to researchers with the development of medical social worker careers can overcome the burnout of medical social workers.

The need to overcome the depersonalization of medical social workers according to researchers is the provision of space to express opinions or conditions of medical social workers 
today so that other professions can find out the duties and workload of medical social workers.

The need to overcome the low personal achievement of work is to increase the HR of medical social workers to serve patients in the Medical Rehabilitation Installation. The smallest award can also help increase the confidence of medical social workers and prevent medical social workers from feeling less maximum in carrying out their work.

The need for the reintegration of the service room can also be seen as analternative in helping medical social workers create maximum service for their patients, by reuniting the service room so that medical social workers can cooperate with each other in fulfilling their duties.

\section{CONCLUSION}

Central General Hospital (RSUP) Dr. Hasan Sadikin is the highest referral hospital in the city of Bandung, West Java. RSUP Dr. Hasan Sadikin serves thousands of patients every day, both outpatients and inpatients. Services provided by Dr. RSUP Hasan Sadikin as the highest referral hospital in Pusan and made various professions work in this hospital. Medical social workers are one such profession.

The medical social worker at RSUP Dr. Hasan Sadikin has been around since 1978. Originally a medical social worker at RSUP Dr. Hasan Sadikin numbered four people, but in the early 2000s, two medical social workers retired so that there were two more medical social workers assigned to work under the Medical Rehabilitation
Installation. Medical social workers also provided direct services to inpatients and outpatients.

Medical social workers have worked at Dr. Hasan Sadikin for 29 years and 19 years. Medical social workers are only two people and are required to provide services in hospitals as big as Dr. Hasan Sadikin makes medical social workers vulnerable to burnout. Patients served by medical social workers everyday range from one to 3 people, this can make medical social make medical social workers do not focus on treating their patients. Burnout experienced by medical social workers can make quality services provided to patients are reduced.

Based on the results of research conducted by researchers regarding the burnout of medical social workers at RSUP Dr. Hasan Sadikin Bandung for approximately one month. Researchers get an overview of the burnout experienced by medical social workers at work. The results of this study were obtained from interviews, observations and documentation studies conducted to medical social workers, medical social worker partners and also patients from medical social workers.

The first aspect that describes the burnout of medical social workers is the emotional fatigue aspect. In the emotional fatigue aspect, medical social workers experience frustration, despair, sadness, saturation, irritability, feeling trapped in work and easily tired. Emotional fatigue felt by medical social workers is caused by obstacles in his career in terms of rising ranks and also working conditions such as the number of patiens and the separation of 
medical social worker service rooms from one another making it difficult to divide tasks and cooperation. The emotional fatigue of medical social workers is not shown to patients.

The second aspect studied is the depersonalization aspect which is described by moving away from the environment, being cynical, apathetic and unfeeling. Based on the results of the study, medical social workers do not show attitude away from the environment and also cynical. This is because medical social workers often selfintrospection when there are problems told to people who are trusted, and pray when exposed to problems. Medical social workers also hold firm their professionalism at work so they always want to show their best despite the many obstacles they experience. The perceived thing is to be callous by social workers because of emotional momentary accumulation of resentment from career barriers. Depersonalization of medical social workers has no effect on patient services.

The last aspect examined is the aspect of low achievement of individual medical social workers, which consists of feeling less than optimal at work, decreased productivity and difficulty in dealing with problems. The only sub-aspect perceived to be a problem is the aspect of feeling less than optimal in providing services. this is due to the lack of human resources of medical social workers and the separation of medical social worker service rooms. The impact that arises is that the stage of assistance for patients cannot be complete and in certain conditions patients become late to be treated.

\section{Recommendation}

The researcher suggests for further research on the Effect of Work Climate on Burnout Medical Social Workers. This is to find out how much influence the working climate is good and conducive in Dr. Hasan Sadikin in influencing burnout experienced by medical social workers. Other advanced research is the effect of the workload of medical social workers on the burnout he feels. This is because medical social workers serve quite a number of patients for many Years but the burnout he felt has never had an impact on patients despite having a lot of workloads.

Azwar, Azrul

\section{REFERENCES}

PengantarAdministrasi Kesehatan. Jakarta: Binarupa Aksara

Bakker, A. B, and Costa, P. L. (2014).Chronic Job Burnout and Daily Functioning: a Theoretical Analysis. Diakses 11 Agustus 2017, dari www.sciencedirect.com/science/article/pi i/S2213058614000096

Caputo, J. S. (1991). Stress and Burnout in Library Service. Phoenix: The Oryx Press

Farber, A. B. (1983). Stress and Burnout in The Human Service Professions. New York: Pergamon Press Inc.

Fereshti Lailani. (2013). Efikasi Diri Sebagai Internal Buffer Terhadap Burnout.Talenta Psikologi, 4(1), 35-58.

Garvin.(1999). Tentang Group Work.(Herry Koswara dkk). Bandung: STKS Press Bandung

Gillespie, D. F. (1987).Burnout Among Social Workers. New York: Routledge

Johnston, Marry. (1988). Relasi Dinamis antara Pekerja Sosial dengan Klien dalam Setting Rumah Sakit. Solo: Sri Laksana Purna

Keputusan Menteri Kesehatan Republik Indonesia Nomor 378/Menkes/SK/2008 
tentang Pedoman Pelayanan Rehabilitasi Medik di Rumah Sakit Kelas A,B,C dan D.

Kustian, Arief. (2013). Burnout Pekerja Sosial dalam Melayani Pasien Psikotik di Rumah Sakit Jiwa Provinsi Jawa Barat.Bandung: STKS Bandung

Lim Bee Ean. (2007). Study On The Job Satisfaction and Burnout Among Medical Social Workers in Government Hospitals in Malaysia. Malaysia: USM

Lexy J. Moleong.(2007). Metodologi Penelitian Kualitatif. Bandung: Remaja Rosdakarya

Maslach, Christina and Michael P. L. (2016).Understanding The Burnout Experience: Recent Research and Its Implications for Psychiatry.Journal World Psychiatry, 15(2), 103-111.

Maslach, Christina, Wilmar B. S. and Michael P. L. (2001).Job Burnout.Annual Rev Psychology, 52, 397-422.

Nuryana, Mu'man.(2001). Pekerjaan Sosial Medik di Rumah Sakit. Jakarta: Departemen Kesehatan dan Kesejahteraan Sosial Republik Indonesia

Schaufeli, B. W., Michael P. L. and Christina Maslach. (2009). Burnout: 35 Years of Research and Practice. Career Development International, 14(3), 204220.

Siti Raudhoh. (2013). Psikoedukasi. Bandung: Universitas Padjajaran.

Sugiyono.(2016). Memahami Penelitian Kualitatif. Bandung: Alfabeta

Suharsimi Arikunto. (2010). Prosedur Penelitian Suatu Pendekatan Pratek. Edisi Revisi V. Jakarta: Rieneka Cipta

Suharto, Edi. (2007). Pekerjaan Sosial di Dunia Industri: Memperkuat CSR (Corporate Social Responsibility). Bandung: Alfabeta

Sukoco, Dwi Heru.(1998). Profesi Pekerjaan Sosial dan Pertolongannya. Bandung: Kopma STKS

Triana Yusuf, Bellinda dan Eryani, Ria Dewi.(2016). Studi Deskriptif Mengenai Burnout pada Perawat di Rumah Sakit
Umum Daerah Kab. Bandung. Prosiding Psikologi, 2(1).

Undang-Undang Republik Indonesia Nomor 36 Tahun 2009 tentang Kesehatan

Virgonita IW, Mulya dan Marleny P, Putri (2015).Pengaruh Psikoedukasi Manajemen Burnout terhadap Strategi Koping Pada Ibu Asuh sebagai Caregiver di SOS Children's Villages Semarang.JURNAL DINAMIKA SOSBUD, 17(2), 285-291 
